\title{
Three-dimensional tomographic reconstruction of atmospheric gravity waves in the mesosphere and lower thermosphere (MLT)
}

\author{
Rui Song ${ }^{1,2}$, Martin Kaufmann ${ }^{1}$, Manfred Ern ${ }^{1}$, Jörn Ungermann ${ }^{1}$, Guang Liu ${ }^{3}$, and Martin Riese ${ }^{1,2}$ \\ ${ }^{1}$ Institute of Energy and Climate Research, Stratosphere (IEK-7), Research Centre Jülich, 52425 Jülich, Germany \\ ${ }^{2}$ Institute for Atmospheric and Environmental Research, University of Wuppertal, 42119 Wuppertal, Germany \\ ${ }^{3}$ Key Laboratory of Digital Earth Sciences, Institute of Remote Sensing and Digital Earth, \\ Chinese Academy of Sciences, Beijing, China
}

Correspondence: Rui Song (r.song@fz-juelich.de)

Received: 24 November 2017 - Discussion started: 1 December 2017

Revised: 19 April 2018 - Accepted: 20 April 2018 - Published: 1 June 2018

\begin{abstract}
Gravity waves (GWs) have been intensively studied over recent decades because of their dominant role in the dynamics of the mesosphere and lower thermosphere (MLT). The momentum deposition caused by breaking GWs determines the basic structure and drives the large-scale circulation in the MLT. Satellite observations provide a way to qualify the properties and effects of GWs on a global scale. As GWs can propagate vertically and horizontally in the atmosphere, resolving both horizontal and vertical wavelengths is important for the quantification of a wave. However, this can hardly be achieved by one instrument with a good spatial coverage and resolution. In this paper, we propose a new observation strategy, called "sweep mode", for a real threedimensional (3-D) tomographic reconstruction of GWs in the MLT by modifying the observation geometry of conventional limb sounding measurements. It enhances the horizontal resolution that typical limb sounders can achieve, while at the same time retaining the good vertical resolution they have. This observation strategy is simulated for retrieving temperatures from measurements of the rotational structure of the $\mathrm{O}_{2}$ A-band airglow. The idea of this observation strategy is to sweep the line of sight (LOS) of the limb sounder horizontally across the orbital track during the flight. Therefore, two-dimensional (2-D) slices, i.e., vertical planes, that reveal the projection of GWs can be observed in the direction along and across the orbital track, respectively. The 3-D wave vector is then reproduced by combining the projected 2-D wave slices in the two directions. The feasibility of this sweepmode tomographic retrieval approach is assessed using simulated measurements. It shows that the horizontal resolution
\end{abstract}

in both along- and across-track directions is affected by an adjustable turning angle, which also determines the spatial coverage of this observation mode. The retrieval results can reduce the errors in deducing momentum flux substantially by providing an unbiased estimation of the real horizontal wavelength of a wave.

\section{Introduction}

The mesosphere and lower thermosphere (MLT, 50 $110 \mathrm{~km}$ ) constitutes the upper part of the middle atmosphere ( $\sim 10-110 \mathrm{~km})$ and is dominated by atmospheric waves, including planetary waves, tides, and gravity waves (GWs; Vincent, 2015). GWs are mainly excited in the lower atmosphere and propagate into the middle and upper atmosphere. As GWs propagate upward and dissipate, they force the large-scale atmospheric circulation, along with considerable influences on the constituents and thermal structures in the MLT region (Lindzen, 1981; Fritts and Alexander, 2003). Parameterizations of these processes are important for reducing the uncertainty in weather and climate prediction models (Alexander et al., 2010; Geller et al., 2013). However, current parameterization schemes are based on simplified assumptions and lack constrains (Medvedev and Klaassen, 2000), resulting in an unrealistic assessment of the effects of GWs. Therefore, various observing techniques have been applied over recent decades to validate the GW parameterization models. 
GWs can be observed from ground or space via the temperature perturbations that they cause in the atmosphere. Characterization of GWs from such temperature measurements first requires the subtraction of a background temperature. The average temperature structure of the atmosphere, as well as several different modes of planetary waves (Ern et al., 2009), and tides (Forbes et al., 2006), contributes to this background temperature. The remaining temperature perturbations are then assumed to be introduced by GWs. Ground-based observation techniques like MF radars (e.g., Hoffmann et al., 2010, 2011), meteor radars (e.g., Fritts et al., 2010; Placke et al., 2011) and airglow imagers (e.g., Nakamura et al., 1999; Pautet and Moreels, 2002; Suzuki et al., 2004, 2010) give information about the local time variations of GWs. Advances in satellite instrumentation have made it possible to measure GWs from a global perspective, allowing for identification of their spectral characterization and geographic distribution (e.g., Preusse et al., 2002; Wu, 2004; Hoffmann and Alexander, 2009; Ern et al., 2004, 2017). However, many of the spaceborne instruments are limited either in vertical or horizontal resolution due to their viewing geometry (Alexander and Barnet, 2007).

Limb sounding is used in many satellite missions because it provides important information about the middle atmosphere dynamics with a good vertical resolution $(\sim 1-3 \mathrm{~km})$. The Sounding of the Atmosphere using Broadband Emission Radiometry (SABER) measures temperature between 20 and $110 \mathrm{~km}$. The observations are sensitive to GWs with horizontal and vertical wavelengths longer than $\sim 100-200$ and $\sim 4 \mathrm{~km}$ (Preusse et al., 2002; Schroeder et al., 2009; John and Kumar, 2012; Liu et al., 2017). The Limb Infrared Monitor of the Stratosphere (LIMS) gave temperature profiles between 15 and $60 \mathrm{~km}$ at a vertical resolution of $1.8 \mathrm{~km}$ (Remsberg et al., 2004). Utilizing the LIMS data, Fetzer and Gille (1994) derived global GW temperature variances with vertical wavelengths of $\sim 6-50 \mathrm{~km}$ and horizontal wavelengths longer than $\sim 200 \mathrm{~km}$. The Global Positioning System (GPS) signals can be used to derive the temperature in the altitude range of $\sim 15-40 \mathrm{~km}$ with the radio occultation technique (Rocken et al., 1997). The derived temperature perturbations have been used by Tsuda et al. (2000) to extract mesoscale GWs with vertical wavelengths of $\sim 2-10 \mathrm{~km}$. The Cryogenic Infrared Spectrometers and Telescopes for the Atmosphere (CRISTA) delivered temperature data from $\sim 20$ to $80 \mathrm{~km}$ (Riese et al., 1999). From these data GWs with vertical wavelengths of $\sim 5-25$ and $\sim 6-30 \mathrm{~km}$ were derived from CRISTA-1 and CRISTA-2, respectively (Eckermann and Preusse, 1999; Preusse et al., 2002). With its high vertical resolution $(<1 \mathrm{~km})$, the High Resolution Dynamics Limb Sounder (HIRDLS) data gave information about GWs with vertical wavelengths of $\sim 2-16 \mathrm{~km}$ in the altitude range of $\sim 20-60 \mathrm{~km}$ (Alexander et al., 2008; Ern et al., 2011). The Solar Occultation for Ice Experiment (SOFIE) onboard the Aeronomy of Ice in the Mesosphere (AIM) satellite measures temperature profiles in the height range of $10-102 \mathrm{~km}$ in the
Arctic and Antarctic. The SOFIE measurements can be used to study seasonal and annual variations of GWs in the entire polar stratosphere and mesosphere in both hemispheres (Liu et al., 2014). Compared to limb sounding or occultation measurements, nadir soundings have a better horizontal resolution but suffer from a poor vertical resolution. They include the Advanced Microwave Sounding Unit (AMSU; Wu, 2004) and the Atmospheric Infrared Sounder (AIRS; Alexander and Barnet, 2007; Hoffmann and Alexander, 2009; Ern et al., 2017). The Cloud Imaging and Particle Size (CIPS) instrument onboard the AIM satellite measures polar mesospheric cloud (PMC) morphology and particle properties. GWs derived from nadir viewing of CIPS have horizontal wavelengths mainly in the range of $250-300 \mathrm{~km}$ (Chandran et al., 2010).

For a better understanding of GW effects, proper observations with both high vertical and horizontal resolutions are required. Typical limb sounders can resolve GW structures with a high vertical resolution by assuming a horizontally homogeneous atmosphere along the line of sight (LOS) of the observations. In the case of a spaceborne platform, the effective length of an atmospheric parcel (i.e., the weighting function) that is scanned by a limb-viewing instrument can extend to a length of a few hundred kilometers along the LOS. This is a major error source for the retrieval of the true state of the atmosphere, especially when the probed region suffers from strong variabilities, e.g., GWs. However, a large part of the horizontal variabilities of the atmosphere can still be accounted for from limb sounding measurements by means of a modified retrieval scheme. The approach of obtaining horizontal structures of GWs applies to the general limb instruments with a fixed viewing angle with respect to the flight track. The basic idea of this approach is to estimate the horizontal wavelength of GWs by combining the phases provided by the wave analysis of adjacent vertical profiles. This approach was proposed by Ern et al. (2004) and was successfully used to retrieve wave temperature amplitudes, vertical wavelengths and projections of horizontal wavelengths in the sampling direction with CRISTA2 measurements, as well as several other datasets (Alexander et al., 2008; Wright et al., 2010; Ern et al., 2011). The shortest horizontal wavelength to be observed is limited by the Nyquist wavelength, which is twice that of the satellite sampling distance. If the LOS is in the direction of the orbital plane, horizontal inhomogeneities along the LOS can be obtained more reliably by applying a 2-D tomographic retrieval scheme. This approach has been used in Michelson Interferometer for Passive Atmospheric Sounding (MIPAS; Carlotti et al., 2001) and Microwave Limb Sounder (MLS; Livesey and Read, 2000). However, even if the horizontal resolution can be improved by such approaches, there is one main limitation that applies for all observations based on a fixed LOS: only the apparent wavelengths along the orbital track are derived. This generally results in a retrieved horizontal wavelength longer than the real wavelength of a wave. 
Therefore, deriving highly resolved three-dimensional (3D) temperature fields would represent a major advance. It would ensure that the resolved GW structures are realistic in terms of wavelength, amplitude, and propagation direction.

A real 3-D tomographic retrieval combining different limb-scanning sequences requires a large number of tangent points in the target atmospheric volume. In the case of an airborne platform, this can be realized by viewing the target volume from different directions, for example by performing closed flight patterns that enclose the target volume, or by panning the viewing direction of the instrument during flight. Such an observation scenario was suggested by Ungermann et al. (2011) and applied by Kaufmann et al. (2015) and Krisch et al. (2017) for an airborne infrared limb sounder. For a spaceborne platform, the feasibility of resolving fine GW structures with tomographic retrievals has been demonstrated using simulated measurements of PREMIER mission (Process Exploration through Measurements of Infrared and millimetre-wave Emitted Radiation; Ungermann et al., 2010). The PREMIER concept is based on infrared limb imaging (Riese et al., 2005), which provides high along-track sampling $(\sim 50 \mathrm{~km})$ and across-track sampling $(\sim 25 \mathrm{~km})$ at the same time by combining novel two-dimensional detector arrays with Fourier spectroscopy (e.g., Friedl-Vallon et al., 2014).

In this paper, we present a new spaceborne observation strategy to detect 3-D atmospheric structures in the MLT region. It is applicable to any temperature limb sounder with vertical imaging capability and ability to change its viewing direction rapidly. The idea of this observation mode is to locate the tangent points in 2-D slices by sweeping the LOS of the instrument in the horizontal plane. The reconstruction of the 3-D atmospheric state is then simplified by performing retrievals of 2-D atmospheric slices that represent the projections of the true atmosphere in two different directions. The observation strategy of this "sweep mode" is introduced in Sect. 2 in more detail. The forward model for this 3-D tomographic retrieval problem is described in Sect. 3. In Sect. 4, a case study of this sweep mode using simulated measurements is presented. The achievable horizontal resolution and coverage, as well as the unbiased estimation of the real horizontal wavelength of a wave from this observational mode is analyzed in Sect. 5. Finally, the conclusion is given in Sect. 6.

\section{Instrument and observation strategy}

This study was designed for an instrument measuring the rotational distribution of the $\mathrm{O}_{2} \mathrm{~A}$-band emission. The $\mathrm{P}$ and $\mathrm{R}$ branch emission lines follows a Boltzmann distribution described by the kinetic temperature under the assumption of local thermodynamic equilibrium (LTE). Kaufmann et al. (2017) described the concept of an instrument based on current nano-satellite platforms that is capable to measure this emission. Depending on the signal-to-noise requirement, this (a)

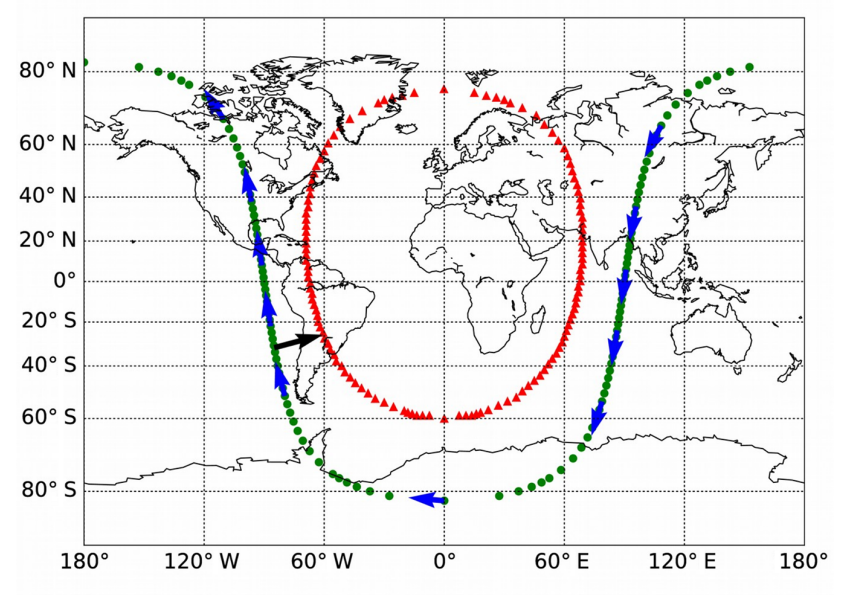

(b)

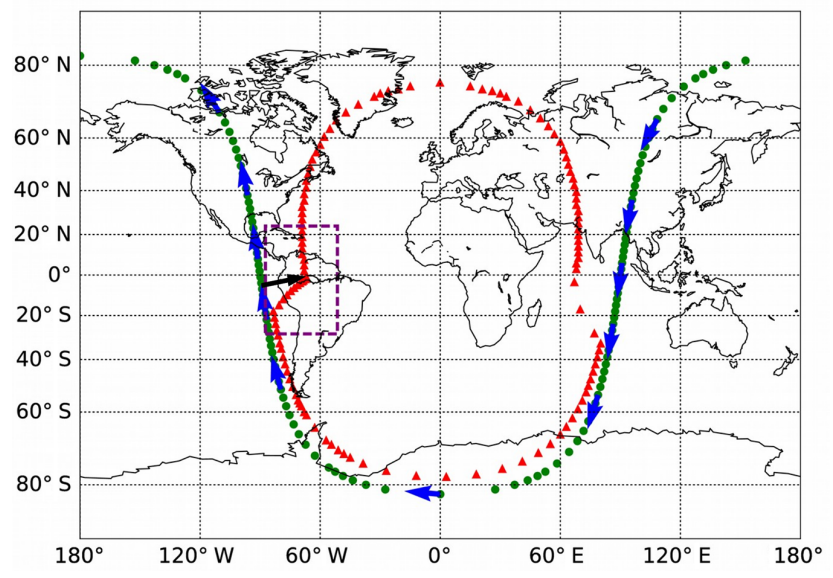

Figure 1. Global observation geometry of an exemplary orbit of (a) conventional limb sounding and (b) sweep-mode limb sounding. The satellite is operated in an orbit at an altitude of $600 \mathrm{~km}$ and inclination of $98^{\circ}$. Satellite positions are sampled by green dots and corresponding tangent points by red triangles. The flight direction of the satellite is shown by blue arrows. The viewing direction of the instrument is represented by black arrows. The viewing angle in (a) is perpendicular to the flight direction, while in (b) changes from 10 to $90^{\circ}$ in the ascending orbit, and decreases back to $10^{\circ}$ in the descending orbit. In (b), the purple-dashed rectangular box represents the region where the sweep mode takes place.

instrument delivers temperature at a vertical resolution of a few hundred meters.

The high-performance attitude control system provides the instrument with the ability to sweep the LOS accurately. While conventional spaceborne limb sounders usually have a constant viewing direction during the flight, this sweep mode is capable of adjusting the LOS from forward looking to backward looking. During the sweeping, a slew rate of $\sim 10^{\circ} \mathrm{s}^{-1}$ provided by the envisaged attitude control sys- 
tem is sufficient for the purpose of sampling the vertical atmospheric profiles along and across the orbital track, respectively. Figure 1 illustrates the orbital track, flight direction, satellite positions, and corresponding tangents points for conventional limb sounding and sweep-mode limb sounding. In this simulation, the satellite is operated in an orbit at an altitude of $600 \mathrm{~km}$ and inclination of $98^{\circ}$. The satellite positions are represented by green dots, and corresponding tangent points are represented by red triangles. The flight direction is indicated by the blue arrows along the orbital track, and the direction of one sample LOS is indicated by the black arrow. The viewing angle, defined as the angle between flight direction and LOS, is a constant value for conventional limb sounding, e.g., $90^{\circ}$ as shown in Fig. 1a. While the viewing angle for sweep mode needs to be adapted in a way such that the two vertical slices are exactly perpendicular to each other. Figure $1 \mathrm{~b}$ shows an example of sweep mode with the viewing angle of the instrument increasing from 10 to $90^{\circ}$ in the region marked by the purple-dashed rectangular box. In this region, a 2-D retrieval scheme is used to resolve small-scale atmospheric structures in the direction along and across the orbit track separately. Consequently, the 3-D GW parameters within this atmospheric volume can be derived by combining the 2-D wave vectors along the two directions mentioned above.

\section{Forward model}

\section{1 $\mathrm{O}_{2}$ A-band airglow emission model}

The oxygen atmospheric band (A-band) airglow emission is used for the temperature measurements within the required altitude range $(\sim 60-120 \mathrm{~km})$. This oxygen band emission is self-absorbed such that radiance from the lower atmosphere or the ground cannot reach the spaceborne instrument. In the MLT region the $\mathrm{O}_{2} \mathrm{~A}$ band becomes optically thin, making it possible to measure this emission from space. There are three primary sources of the excited oxygen state $\mathrm{O}_{2}\left(b^{1} \Sigma, v=0\right)$ in the MLT region, which lead to the A-band emission. The first source is through the A-band $(762 \mathrm{~nm})$ and B-band $(689 \mathrm{~nm})$ resonant absorption from the ground state $\mathrm{O}_{2}\left(X^{3} \Sigma, v=0\right)$ :

$\mathrm{O}_{2}\left(X^{3} \Sigma, v=0\right)+h v \rightarrow \mathrm{O}_{2}\left(b^{1} \Sigma, v=0,1\right)$.

The $\mathrm{B}$ band is considered due to the fact that $\mathrm{O}_{2}\left(b^{1} \Sigma\right)$ in the $v=1$ state is rapidly collisionally deactivated into the $v=0$ state, subsequently leading to A-band emission. The second source is through the collision of $\mathrm{O}_{2}\left(X^{3} \Sigma, v=0\right)$ with $\mathrm{O}\left({ }^{1} \mathrm{D}\right)$ :

$\mathrm{O}_{2}\left(X^{3} \Sigma, v=0\right)+\mathrm{O}\left({ }^{1} \mathrm{D}\right) \rightarrow \mathrm{O}\left({ }^{3} P\right)+\mathrm{O}_{2}\left(b^{1} \Sigma\right)$.

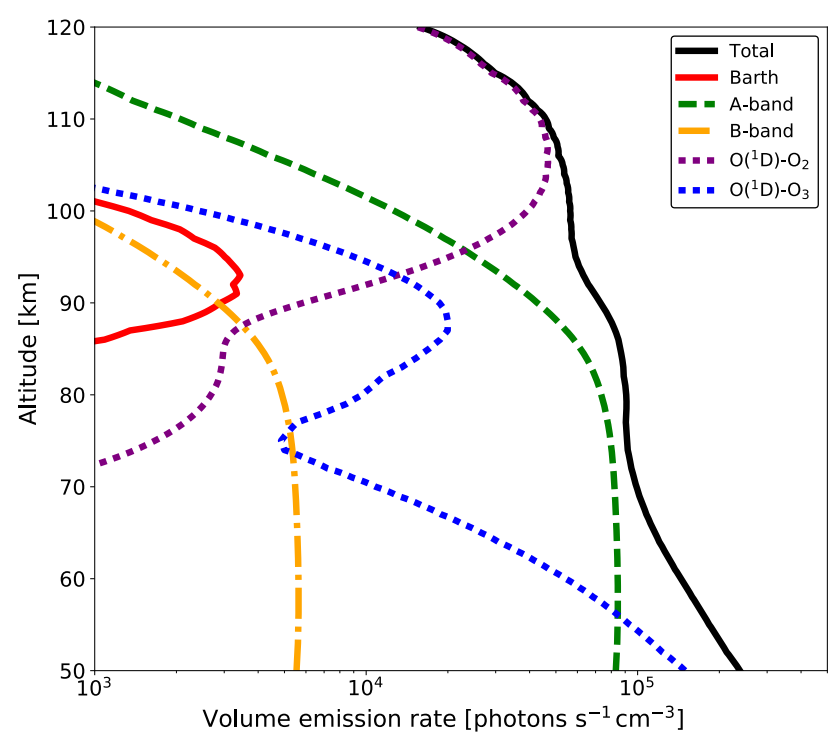

Figure 2. Modeled $\mathrm{O}_{2}$ A-band dayglow emission profile at $30^{\circ} \mathrm{N}$ and $220^{\circ} \mathrm{E}$ for $14: 40$ local solar time simulated from the HAMMONIA model. A band and B band (dashed green line and dotdashed orange line, respectively) are the contributions from the resonant absorption. $\mathrm{O}\left({ }^{1} \mathrm{D}\right)-\mathrm{O}_{2}$ and $\mathrm{O}\left({ }^{1} \mathrm{D}\right)-\mathrm{O}_{3}$ (dotted purple line and blue line, respectively) are the contributions from the collision with $\mathrm{O}\left({ }^{1} \mathrm{D}\right)$. The solid red line is the contribution from the Barth process. The black curve denotes the total A-band emission.

The third source of $\mathrm{O}_{2}\left(b^{1} \Sigma\right)$ is a two-step Barth process, in which an excited molecule $\mathrm{O}_{2}^{*}$ is created from atomic oxygen first, and afterward $\mathrm{O}_{2}\left(b^{1} \Sigma\right)$ is produced by quenching.

$\mathrm{O}+\mathrm{O}+\mathrm{M} \rightarrow \mathrm{O}_{2}^{*}+\mathrm{M}$
$\mathrm{O}_{2}^{*}+\mathrm{O}_{2} \rightarrow \mathrm{O}_{2}\left(b^{1} \Sigma\right)+\mathrm{O}_{2}$

The Barth process is independent of solar radiation, and therefore is the only mechanism that produces $\mathrm{O}_{2}\left(b^{1} \Sigma, v=\right.$ 0 ) during nighttime. Figure 2 shows a typical vertical profile reflecting the volume emission rate of modeled $\mathrm{O}_{2}$ Aband dayglow, along with the relevant excitation processes described above. The background atmosphere (temperature $T$, number density of $\mathrm{O}, \mathrm{O}_{2}, \mathrm{O}_{3}$, and $\mathrm{N}_{2}$ ) is taken from the Hamburg Model of the Neutral and Ionized Atmosphere (HAMMONIA) model (Schmidt et al., 2006) run at $30^{\circ} \mathrm{N}$ and $220^{\circ} \mathrm{E}$ for 14:40 local solar time. As shown in Fig. 2, the $\mathrm{O}_{2}$ A-band volume emission rate $\eta$ has a broad maximum of $\sim 10^{5}$ photons s ${ }^{-1} \mathrm{~cm}^{-3}$ from 50 to $100 \mathrm{~km}$, with exponential decrease above that. Since the $\mathrm{O}_{2}\left(b^{1} \Sigma, v=0\right)$ has a lifetime of approximately $12 \mathrm{~s}$, it is generally assumed that the molecule is in rotational local-thermodynamic equilibrium (Vallance Jones, 1974). Therefore, the kinetic temperature of the atmosphere can be derived from the rotational band structures of the emissions. As a consequence of the rotational band structure, the number of emitted photons is distributed into narrow emission lines within the band, rep- 


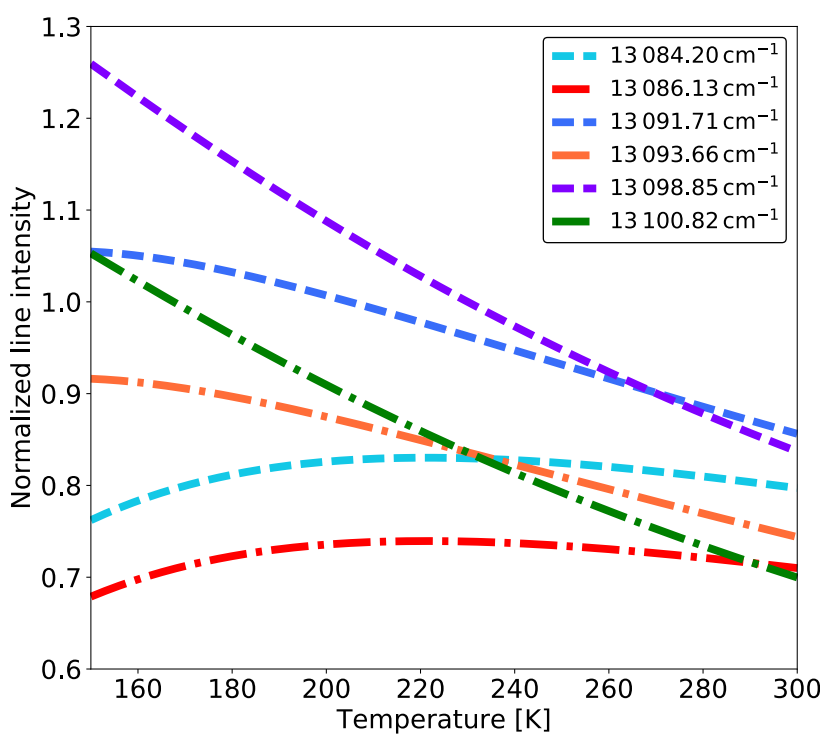

Figure 3. Temperature dependence of six rotational lines of the $\mathrm{O}_{2}$ A-band emission. The center wavenumbers of individual lines are given in the figure legend. The intensity is normalized around the maximum intensity for a temperature of $230 \mathrm{~K}$.

Table 1. Constants for $\mathrm{O}_{2}$ A-band rotational structure calculation (Rothman et al., 2013).

\begin{tabular}{lrrr}
\hline$v, \mathrm{~cm}^{-1}$ & $E^{\prime \prime}, \mathrm{cm}^{-1}$ & $A^{\prime}, \mathrm{s}^{-1}$ & $g^{\prime}$ \\
\hline 13084.203 & 190.775 & $2.506 \times 10^{-2}$ & 21.0 \\
13086.125 & 188.853 & $2.232 \times 10^{-2}$ & 21.0 \\
13091.710 & 130.438 & $2.581 \times 10^{-2}$ & 17.0 \\
13093.656 & 128.492 & $2.242 \times 10^{-2}$ & 17.0 \\
13098.848 & 81.581 & $2.701 \times 10^{-2}$ & 13.0 \\
13100.822 & 79.607 & $2.258 \times 10^{-2}$ & 13.0 \\
\hline
\end{tabular}

resented by $\eta_{\text {rot }}$. Babcock and Herzberg (1948) discussed the fine structure of $\mathrm{O}_{2}$ A-band emission in details, and equations for calculating the emission spectrum were summarized in Song et al. (2017) from Eqs. (4)-(5). Within this airglow emission spectrum, a subset of six emission lines has proven to give an optimal setup for a potential satellite mission aiming to derive the kinetic temperature. The physical parameters used for this fine structure calculation are provided by the high-resolution transmission molecular absorption database (HITRAN 2012; Rothman et al., 2013) and listed in Table 1. They include wavenumber $v$, lower state energy $E^{\prime \prime}$, Einstein coefficient $A^{\prime}$, and upper state degeneracy $g^{\prime}$. The lines were chosen so that both positive and negative temperature dependencies of rotational line emission intensity are distinct. Plots of normalized rotational line emission intensity as a function of temperature are shown in Fig. 3.

\subsection{Wave perturbation}

The temporal and spatial variability of the airglow emission are affected by the changes in constituents and temperature due to upward propagating GWs. Considering an adiabatic and windless atmosphere, the temperature perturbation $T^{\prime}$ at position $(x, y, z)$ induced by a monochromatic wave can be written as (Fritts and Alexander, 2003):

$T^{\prime}(x, y, z, t)=\hat{T} \cos \left(\frac{2 \pi x}{\lambda_{x}}+\frac{2 \pi y}{\lambda_{y}}+\frac{2 \pi z}{\lambda_{z}}-\hat{\omega} t\right)$,

where $\hat{T}$ is the wave amplitude, $\hat{\omega}$ the intrinsic frequency, $\lambda_{z}$ the vertical wavelength, $\lambda_{x}$ and $\lambda_{y}$ the horizontal wavelengths in $x$ and $y$ directions, respectively. The number densities of various constituents that contribute to the $\mathrm{O}_{2} \mathrm{~A}$-band airglow emission are also affected by the GW. Ward (1999) proposed a model to simulate the perturbations of airglow taking into account the effects from both the temperature and relevant constituents. The GW induced perturbation on the $\mathrm{O}_{2}$ A-band airglow emission at position $(x, y, z)$ can be calculated with this model.

\subsection{Radiative transfer}

The spectral irradiance $I(v)$ observed by the instrument is a path integral along the LOS, in photons $\mathrm{s}^{-1} \mathrm{~cm}^{-2}$ :

$$
\begin{aligned}
I(v) & =\int_{-\infty}^{\infty} \eta(s)_{\operatorname{rot}} D(v, s) \\
& \exp \left[-\int_{s}^{\infty} n\left(s^{\prime}\right) \sigma\left(s^{\prime}\right) D(v, s) \mathrm{d} s^{\prime}\right] \mathrm{d} s,
\end{aligned}
$$

where $n$ is the $\mathrm{O}_{2}$ number density and $\sigma$ is the absorption cross section. $s$ represents the propagation path through the atmosphere to the instrument along the LOS. The Doppler broadening at wavenumber $v$ is characterized by the function $D(v)$. The pressure broadening and other sources of light (i.e., stray light, scattered sunlight) are ignored in this case.

This propagation path $s$ consists of a set of points at the crossings of the LOS with specified atmospheric grids, along with the distance between neighboring points. As the satellite instrument is above the atmosphere, this geometrical calculation starts at the point where the ray enters the top of the atmosphere and ends where it leaves the top of the atmosphere. This path is then tracked backwards for the calculation of radiation absorption as shown in Eq. (5). Atmospheric Radiative Transfer Simulator (ARTS) is free open-source programming software (Buehler et al., 2005), and it allows the simulation for ray tracing through a 1-D, 2-D, or 3-D atmosphere. In our study, we use ARTS for a fast 3-D ray tracing of the instrument LOS. 
The $\mathrm{O}_{2}$ A-band emission is self-absorbed through the atmosphere. Above the stratopause $(\sim 50 \mathrm{~km})$, only the thermal Doppler broadening $D(v)$ at each emission line is significant and considered for the absorption calculation:

$D(v)=\frac{1}{\alpha_{\mathrm{D}} \sqrt{\pi}} \exp \left[-\frac{\left(v-v_{0}\right)^{2}}{\alpha_{\mathrm{D}}^{2}}\right]$

where $v_{0}$ is the central wavenumber of individual emission lines. The Doppler half-width at half-maximum is $\alpha_{\mathrm{D}} \sqrt{\ln 2}$, with $\alpha_{\mathrm{D}}$ defined as

$\alpha_{\mathrm{D}}=v_{0} \sqrt{\frac{2 k_{\mathrm{B}} T}{m c^{2}}}$,

where $c$ is the speed of light, $k_{\mathrm{B}}$ is Boltzmann's constant, $m$ is the weight of molecular oxygen, and $T$ is the atmospheric temperature at position $s$. Instead of a regular wavenumber grid spacing, an adaptive grid spacing is used for the absorption calculation in our study. Specifically, a finer grid spacing is used in the range near the line center and a coarser grid spacing is used along the wings of the Doppler function. This adaptive grid spacing reduces the computational cost and is sufficient for an accurate estimation of the atmospheric attenuation caused by absorption. The difference between adaptive grid spacing and regular grid spacing in spectrum-integrated intensity is less than $1 \%$.

The irradiance received by the instrument is dependent on the temperature and the $\mathrm{O}_{2}$ density at the tangent altitude. The temperature and $\mathrm{O}_{2}$ can determine the airglow emission rate, as well as the amount of self-absorption. Figure 4 shows the irradiance response $(\Delta I(v) / I(v))$ to a temperature perturbation $(\Delta T)$ of $10 \mathrm{~K}$ at tangent altitudes ranging from 60 to $119 \mathrm{~km}$ with a $1 \mathrm{~km}$ interval at individual emission lines. The constituents perturbation induced by the $\Delta T$ is considered utilizing the model presented in Sect. 3.2. The irradiance response of the strong line (e.g., 13098.85 and $13100.82 \mathrm{~cm}^{-1}$ ) to temperature perturbations is relatively weak $(<6 \%$ ) for tangent altitudes below $87 \mathrm{~km}$ due to strong self-absorption. Above $110 \mathrm{~km}$, the sensitivity of the irradiance response to temperature perturbations reduces because of the decrease in the total amount of $\mathrm{O}_{2}$ A-band emission. Therefore, in this study the atmospheric temperature is retrieved between 87 and $110 \mathrm{~km}$ to ensure a moderate sensitivity to small temperature perturbations.

\section{Numerical experiments}

The retrieval scheme adopted for solving this 3-D tomographic inverse problem has been summarized in Song et al. (2017). The Levenberg-Marquardt iteration method is used to minimize the cost function of the nonlinear problem. The Tikhonov regularization is used to ensure that a unique and

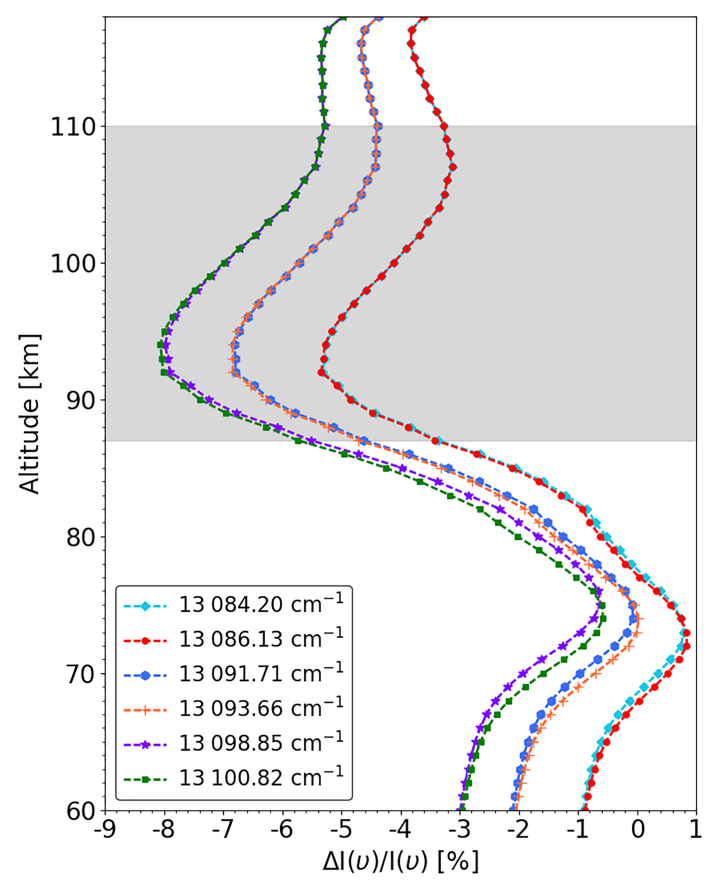

Figure 4. Response of irradiance $(\Delta I(v) / I(v))$ to temperature $(\Delta T=10 \mathrm{~K})$ at different tangent altitudes for individual emission lines. The tangent altitudes covered by the grey shaded area (87$110 \mathrm{~km}$ ) has a higher sensitivity of the irradiance to temperature changes.

physically meaningful solution can be obtained. In this section, we use an example to show an end-to-end simulation of the sweep-mode tomographic observations. The capability of resolving 3-D wave structures from projected 2-D wave slices are explored. The parameters relevant for the observation geometry and atmospheric condition are introduced in Sect. 4.1 and 4.2 , respectively.

\subsection{Observation geometry setup}

The simulation is based on a $600 \mathrm{~km}$ Sun-synchronous orbit with an inclination angle of $98^{\circ}$. In this simulation, the tangent points are sampled with an altitude step of $1.5 \mathrm{~km}$ between 60 and $120 \mathrm{~km}$, and the integration time is assumed to be $6 \mathrm{~s}$ for $\mathrm{O}_{2} \mathrm{~A}$-band dayglow measurements. The measurement track and tangent point distribution of this sweep mode are illustrated in Fig. 5a. It provides a visual clue for the distribution characteristics of the tangents points in the sweep mode. The solid lines represent the projection of the LOS near the tangent point, i.e., an altitude range $70-71 \mathrm{~km}$, on a horizontal plane from consecutive measurements. The locations of corresponding tangent points are marked as black circles. In this example, the instrument is operated in the conventional mode with a viewing angle of $0^{\circ}$ before the sweep mode is activated. After activating the sweep mode, the instrument starts to increase its viewing angle from $0^{\circ}$ towards a turning angle of $45^{\circ}$. Figure $5 \mathrm{~b}$ shows the viewing angle 

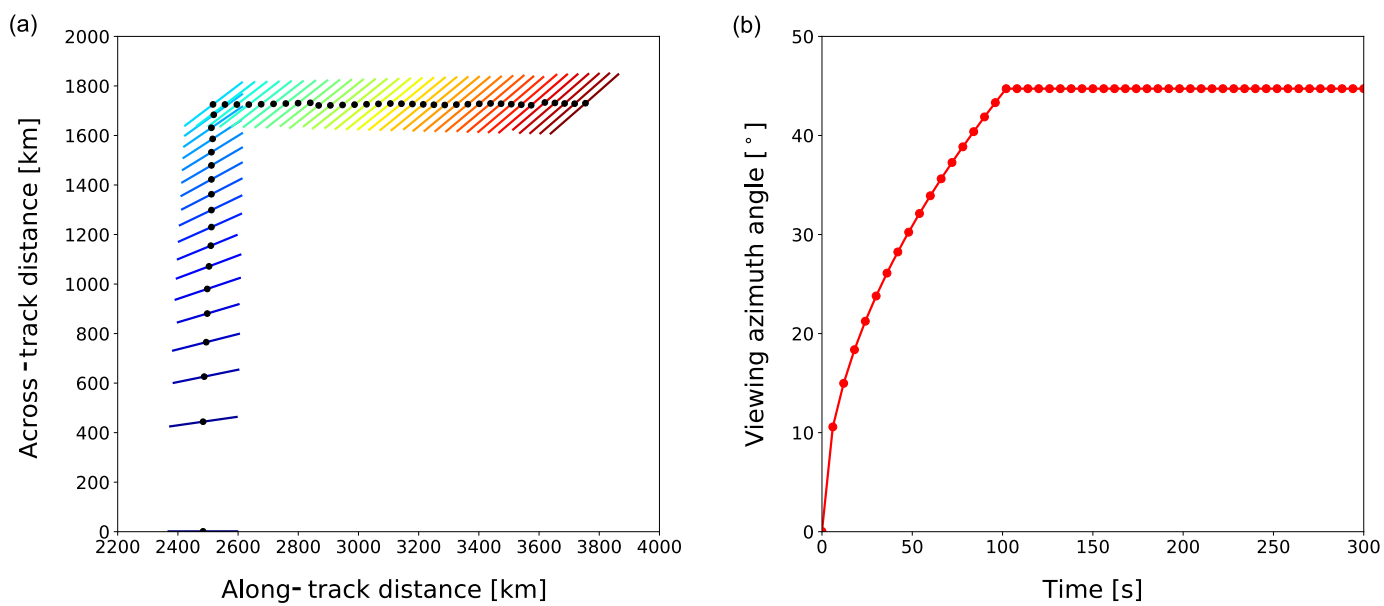

Figure 5. Illustration of the sweep-mode central measurement track (a) and viewing angle variations (b). Flight direction is to the right, $0^{\circ}$ viewing direction is to the right as well. For a single measurement, the LOS that targets at $70 \mathrm{~km}$ tangent altitude is traced. In (a), the solid lines indicate the segments of propagation paths between 70 and $71 \mathrm{~km}$ in the atmosphere. The locations of corresponding tangent points are represented by black circles.

variations of the measurements taken in the sweep mode. This sweep mode is initiated with a viewing angle of $\alpha_{0}=0^{\circ}$ and a slew rate of $\omega=\omega_{0}$ at $t_{0}=0 \mathrm{~s}$. This slew rate slows down gradually such that the tangent points for each imaging are arranged perfectly perpendicular to the orbital track. At time $t$, the viewing angle of the instrument is

$\alpha_{t}=\arccos \left(\frac{L-v t}{L}\right)$

where $L$ is the distance between the tangent point and the satellite position, $v$ is the speed of the satellite. This viewing angle keeps increasing until the predefined turning angle of $45^{\circ}$ has been reached at $t=100 \mathrm{~s}$. After that, the satellite operates again in the conventional mode with a newly set viewing angle of $45^{\circ}$ in the subsequent orbital track. Considering a $L$ of $\sim 2600 \mathrm{~km}$, an $1^{\circ}$ error in the turning angle can result in a $\sim 45 \mathrm{~km}$ offset of the tangent points in the horizontal plane.

\subsection{Atmosphere setup}

In this simulation, the forward model calculates radiance in a 3-D volume at tangent altitudes between 60 and $120 \mathrm{~km}$ on a $250 \mathrm{~m}$ vertical grid. In the horizontal direction, the spacing of the along- and across-track grid of the model is $5 \mathrm{~km}$. This finely sampled atmospheric grid is essential for an accurate simulation of the radiation received by the instrument along the LOS. In the retrieval model, the temperature fields are estimated on two 2-D volumes: one in the across-track direction and another in the along-track direction. In the 2-D retrieval volume, the vertical spacing is $500 \mathrm{~m}$ and the horizontal spacing is $12.5 \mathrm{~km}$.

\subsection{Three-dimensional tomographic retrieval}

This section describes the implementation of the presented principles of sweep-mode tomographic reconstruction in the numerical model. In this simulation, we examined the retrieval results by analyzing the extracted wave amplitude and wavelengths, with special attention paid to how well the horizontal wavelengths can be reproduced along the given directions.

To illustrate the performance of the new observation mode, we perturbed a background atmosphere with a GW, as shown in Fig. 6. The simulated GW has a vertical wavelength of $15 \mathrm{~km}$ and a horizontal wavelength of $310 \mathrm{~km}$ tilted at an angle of $38.6^{\circ}$ away from the flight direction. The left panels in Fig. 6 represent the corresponding 2-D slices extracted from the 3-D atmosphere in the across-track direction. The a priori data, which are assumed to be the same as the background data, are depicted in Fig. 6a. A GW-induced temperature perturbation with an amplitude of $10 \mathrm{~K}$ (Ehard et al., 2015) is depicted in Fig. 6b. The locations of the tangent points from corresponding measurements are marked as white circles. As we can see, the tangent points have a smaller horizontal sampling distance in the region further apart from the orbital track. The retrieved temperature perturbation is shown in Fig. 6c. It is obvious that the retrieved wave has a smoother-looking wave pattern in the part with longer acrosstrack distance, due to a denser horizontal sampling rate in this direction. To deduce the wavelength and amplitude of the retrieved GW, all atmospheric points are fitted against the modulated waves using a least-squares best fit. In order to obtain optimal values, the vertical and horizontal wavelengths of the fitted sine wave are sampled at an interval of $0.1 \mathrm{~km}$, and the amplitude is set as a free parameter for the best-fit calculation. After this best-fit processing, an optimized wave with a 

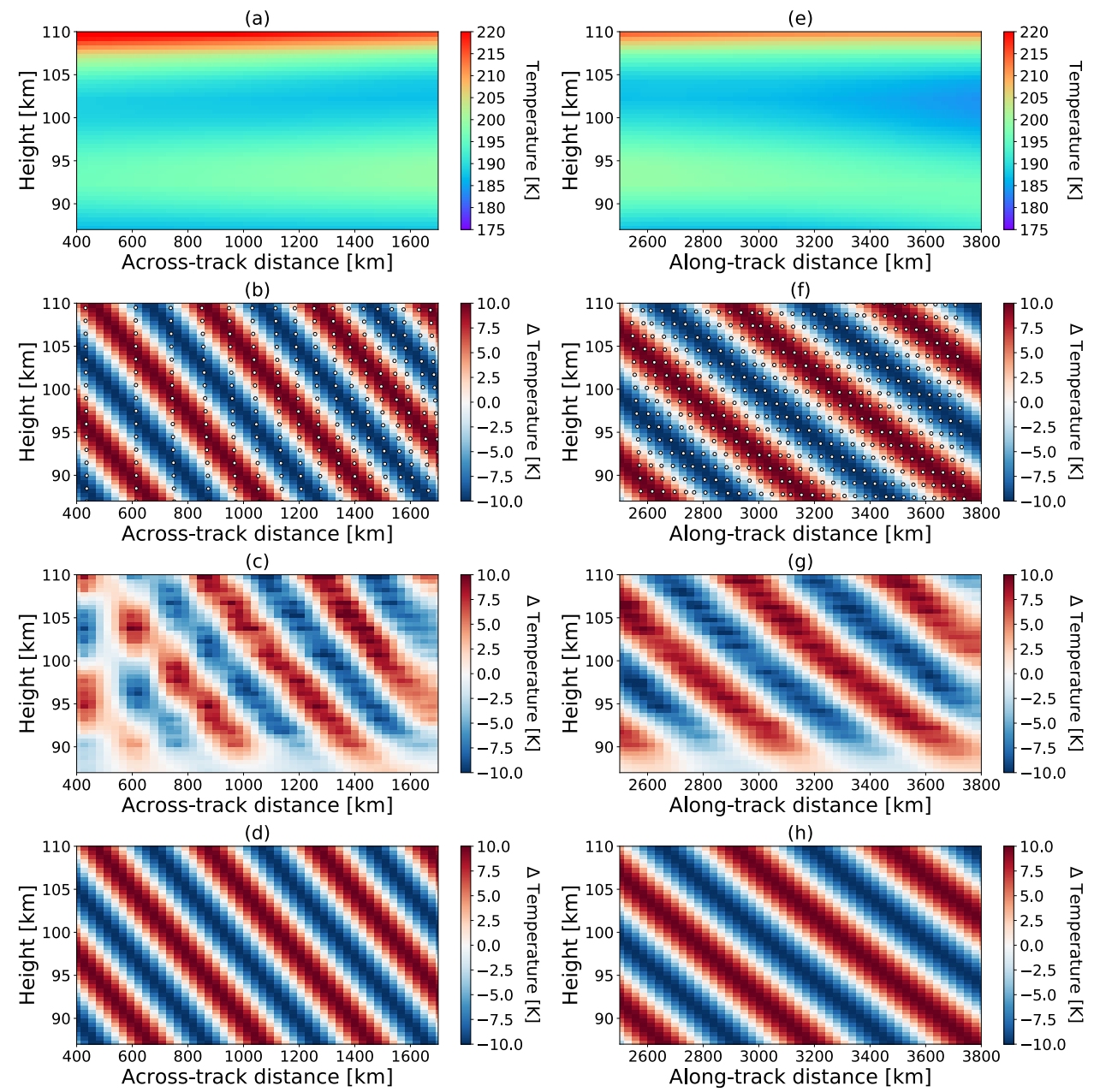

Figure 6. Example of sweep-mode tomographic retrieval a priori, simulated true state, and results using simulated data. The background atmosphere is taken from the HAMMONIA run from 134 to $156^{\circ} \mathrm{W}$ and from $4^{\circ} \mathrm{S}$ to $19^{\circ} \mathrm{N}$. The panels in the left column are 2-D slices extracted from the 3-D atmospheric volume in the across-track direction, while those in the right column are extracted from the along-track direction. The panels in the first row depict the a priori atmosphere. The panels in the second row show the simulated wave structures, along with the tangent points from individual measurements marked as white circles. The panels in the third row show the retrieved temperature perturbations. The panels in the last row depict the optimized wave structures after best-fit processing.

vertical wavelength of $15.2 \mathrm{~km}$, an across-track wavelength of $396.6 \mathrm{~km}$, and an amplitude of $8.2 \mathrm{~K}$ is obtained, as shown in Fig. 6d. In contrast, the panels in the right column show the 2-D along-track slices of the background atmosphere, simulated, retrieved, and fitted wave structures, respectively. From Fig. 6f, one can clearly see consecutive measurements with a constant horizontal sampling rate in that direction. This results in a smooth retrieved wave structure over the entire region of interest, as shown in Fig. 6g. The optimized wave has a vertical wavelength of $15.1 \mathrm{~km}$, an along-track wavelength of $498.2 \mathrm{~km}$ and an amplitude of $8.3 \mathrm{~K}$.

Figure 7 shows a single vertical profile of retrieved temperature at one location and the total deviation from the expected profile including all error sources at altitudes between 87 and $110 \mathrm{~km}$. The error components considered in this simulation arise from the gridding error (discretization of the retrieval grid), the smoothing error, and mainly from the measurement noise. Temperature retrievals below $87 \mathrm{~km}$ and above $110 \mathrm{~km}$ are excluded from the results because of the decreased sensitivity to small temperature perturbations. The temperature is retrieved with a precision better than $2 \mathrm{~K}$ within this altitude range. This uncertainty value allows for the derivation of small-scale atmospheric structures from the temperature perturbations.

The spatial response of the retrieval result is characterized by the averaging kernel matrix $\mathbf{A}$ given by

$$
\mathbf{A}=\left(\mathbf{S}_{a}^{-1}+\boldsymbol{f}^{\prime}(\boldsymbol{x})^{T} \mathbf{S}_{\epsilon}^{-1} \boldsymbol{f}^{\prime}(\boldsymbol{x})\right)^{-1} \boldsymbol{f}^{\prime}(\boldsymbol{x})^{T} \mathbf{S}_{\epsilon}^{-1} \boldsymbol{f}^{\prime}(\boldsymbol{x}),
$$



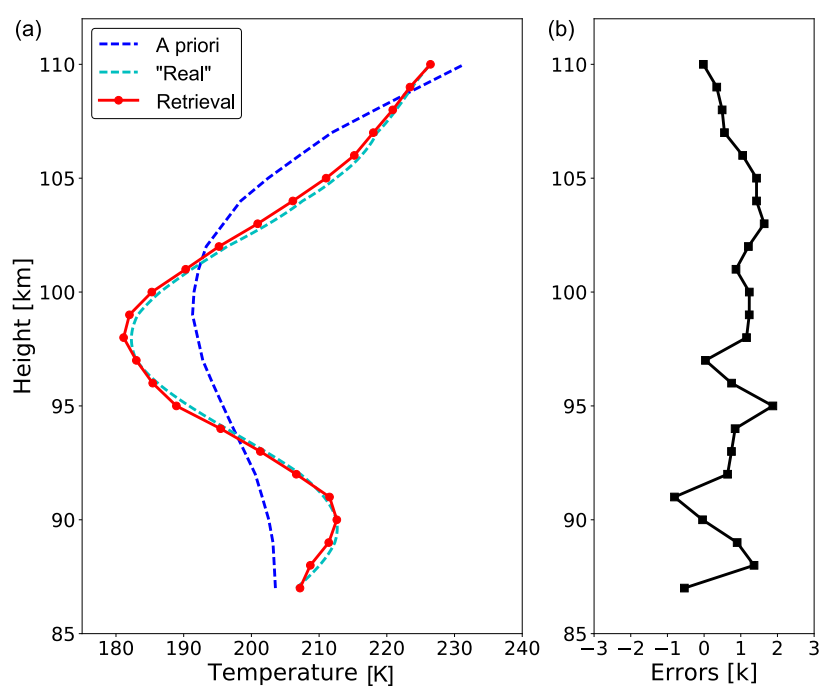

Figure 7. Vertical profile of retrieved temperature (a) and total deviation from the expected profile including all error sources (b).

where $f^{\prime}$ is the Jacobian matrix of the forward model $f$ calculated at atmospheric state $\boldsymbol{x}$. $\mathbf{S}_{a}^{-1}$ is the regularization matrix used to constrain the solution. Here, we used a combination of zeroth- and first-order Tikhonov regularization (Tikhonov and Arsenin, 1977). $\mathbf{S}_{\epsilon}^{-1}$ is the covariance matrix of measurement errors and is assumed to be diagonal. The spatial dispersion of the retrieved data point is measured by a single row of the averaging kernel matrix. Each element in the row describes how and where the retrieval is influenced by the true state of the atmosphere. Figure 8 shows a row of the averaging kernel matrix after mapped into a 2-D space according to the vertical and horizontal coordinates. The spatial resolution of the retrieved data point is estimated by calculating the full width at half-maximum (FWHM) of the row of the averaging kernel matrix along the vertical and horizontal directions, respectively.

In Fig. 8, panel (a) shows the averaging kernel of the retrieval in across-track direction for a tangent point located at $96 \mathrm{~km}$ vertically and $1600 \mathrm{~km}$ across track. The estimated vertical and horizontal resolution are $\sim 1.2$ and $\sim 95 \mathrm{~km}$, respectively. The averaging kernel in the along-tack direction is shown in panel (b) at the position of $96 \mathrm{~km}$ vertically and $3200 \mathrm{~km}$ along track. The estimated vertical and horizontal resolution are $\sim 1.2$ and $\sim 80 \mathrm{~km}$, respectively.

\section{Horizontal wavelength analysis}

GW momentum flux can be estimated from temperature measurements. Based on GW polarization relations, Ern et al. (2004) related GW momentum flux with retrieved temperature amplitude and vertical and horizontal wavelengths. Con- sidering a medium-frequency wave $(N \gg \hat{\omega} \gg f)$, the GW momentum flux is given by

$F=\frac{1}{2} \bar{\varrho} \frac{k}{m}\left(\frac{\mathrm{g}}{N}\right)^{2}\left(\frac{\hat{T}}{T}\right)^{2}$

where $\mathrm{g}$ is the gravity acceleration, $N$ is the buoyancy frequency, and $\hat{T}$ and $T$ are the temperature amplitude and background temperature, respectively. $k=2 \pi / \lambda_{\mathrm{h}}$ is the horizontal wavenumber and $m=2 \pi / \lambda_{\mathrm{v}}$ is the vertical wavenumber of the wave. Therefore, the momentum flux of a GW can be determined if the full wave vector and temperature amplitude are able to be retrieved from the measurements. The retrieval approach for the derivation of vertical wavelength and amplitude of a GW is well established, and therefore further discussion is not given in the paper. In this section, we focus on the assessment of how well the horizontal wave vector can be reproduced from this sweep-mode tomographic retrieval.

\subsection{Along-track horizontal wavelength}

In Sect. 4, the numerical experiments are simulated for the sweep-mode measurements with a specific turning angle of $45^{\circ}$. However, this turning angle $\alpha$ is flexible and can be adjusted between 0 and $90^{\circ}$ according to the target area. Here, the performance of the along-track wavelength retrieval in two extreme cases of $\alpha=0$ and $\alpha=90^{\circ}$ is discussed.

When $\alpha=90^{\circ}$, the tangent points for along-track wavelength analysis extend to $\sim 2500 \mathrm{~km}$ apart from the orbital plane. For individual measurements, the LOS is perpendicular to the along-track direction in this case. This means all the radiation received by the instrument comes from the atmosphere in the across-track direction. For this viewing geometry, 1-D vertical temperature profiles are retrieved from individual measurements independently. The horizontal wavelength is then estimated by analyzing the phases of adjacent vertical temperature profiles (Ern et al., 2004). In this case, the along-track horizontal wavelength that can be detected is limited by the Nyquist wavelength, which is twice the sampling distance: $\lambda_{\mathrm{h}, N}=2 \Delta x_{\mathrm{h}}$. Considering the integration time of $\sim 6 \mathrm{~s}$ in this simulation, GWs with horizontal wavelength longer than $\sim 85 \mathrm{~km}$ in the along-track direction can be detected.

If the turning angle $\alpha$ is smaller than $90^{\circ}$, more information from neighboring atmospheric volume in the along-track direction will contribute to the total radiation received by the instrument. When $\alpha=0^{\circ}$, the LOSs of measurements will overlap with each other in the orbital plane. Figure 9 shows an example of the central measurement track for a vertical sampling of $3 \mathrm{~km}$ and horizontal sampling of $165 \mathrm{~km}$ projected onto the background atmosphere. Such an observation strategy allows for the retrieval of GWs in a real 2-D space. Assuming the same atmospheric condition and viewing geometry, Song et al. (2017) demonstrated that a GW with a horizontal wavelength longer than $150 \mathrm{~km}$ can be re- 


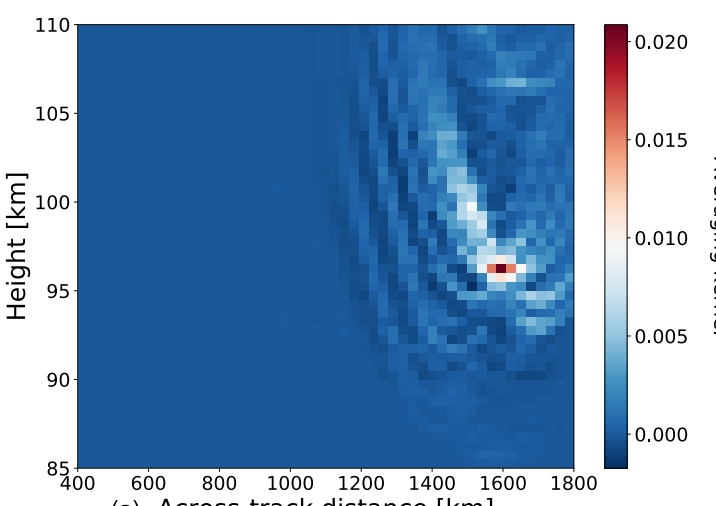

(a) Across-track distance $[\mathrm{km}]$

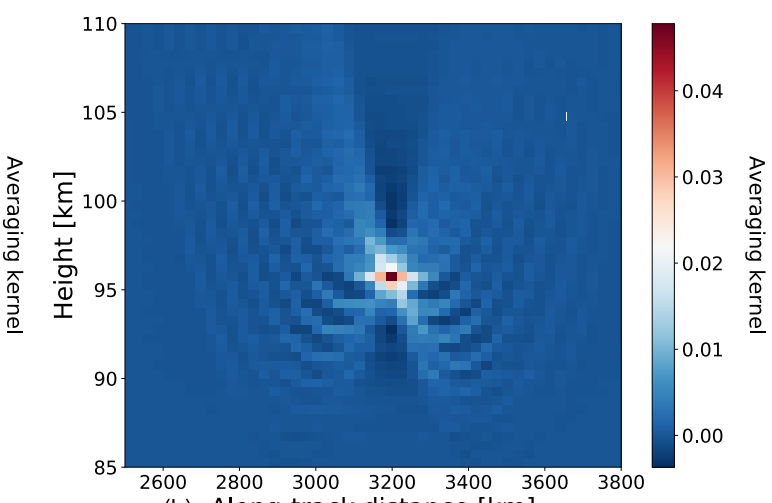

(b) Along-track distance $[\mathrm{km}]$

Figure 8. Averaging kernel matrix for retrieval points in the across-track slice (a) and along-track slice (b). Panel (a) is for the point located at $96 \mathrm{~km}$ vertically and $1600 \mathrm{~km}$ across track, and (b) is for the points locating $96 \mathrm{~km}$ vertically and $3200 \mathrm{~km}$ along track.

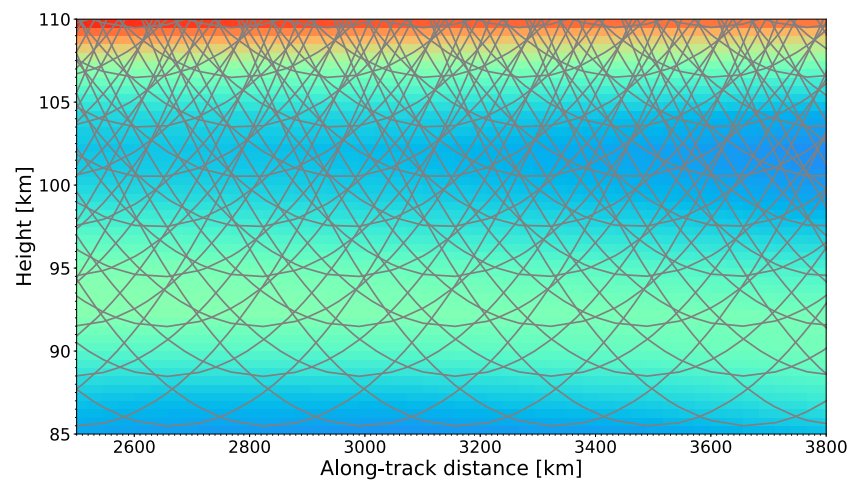

Figure 9. Central track of limb sounding measurements with a viewing azimuth angle of $0^{\circ}$. Note that just for display in this figure the sampling distance is $3 \mathrm{~km}$ in the vertical and $165 \mathrm{~km}$ in the along-track direction. However, the simulated sweep mode has a better spatial resolution: $1.5 \mathrm{~km}$ in the vertical and $40 \mathrm{~km}$ in the along-track direction.

trieved if the horizontal sampling distance is assumed to be $70 \mathrm{~km}$. The actual horizontal sampling distance is $40 \mathrm{~km}$ in our case, and therefore the shortest horizontal wavelength that can be detected is expected to be $\sim 85 \mathrm{~km}$. Note that the detectable along-track horizontal wavelength in the two cases $\left(\alpha=0\right.$ and $\alpha=90^{\circ}$ ) has a similar limit of $\sim 85 \mathrm{~km}$ but is derived from different approaches. When $\alpha=90^{\circ}$, the horizontal wavelength is indirectly deduced from 1-D vertical profiles. However, a full 2-D wave structure can be obtained from tomographic retrieval approach while $\alpha=0^{\circ}$. In Fig. 10, an example of retrieving a $\mathrm{GW}$ with a vertical wavelength of $10 \mathrm{~km}$ and horizontal wavelength of $150 \mathrm{~km}$ is given. In this example, the atmospheric temperature is retrieved in a finer grid: $500 \mathrm{~m}$ in the vertical and $7 \mathrm{~km}$ in the along-track direction. The 2-D wave structure along the orbital plane can be observed clearly.

Additionally, the influence of the across-track variations should also be taken into consideration when the wave is re- solved in the along-track direction. As in this case the retrieval assumes a homogeneous atmosphere in the acrosstrack direction, the resolved temperature fields in the alongtrack direction will be affected by ignoring the across-track variations. For example, turning angles of 45 and $90^{\circ}$ have different weighting functions in the across-track direction. Thus, the temperature fields in the along-track direction that are reconstructed from them will differ from each other. In Fig. 11, a GW is simulated with a vertical wavelength of $15 \mathrm{~km}$ and a horizontal wavelength of $425 \mathrm{~km}$. The wave vector is tilted at an angle of $32^{\circ}$ away from the flight direction. Figure $11 \mathrm{a}$ and $\mathrm{b}$ show the reconstructed wave structures in the along-track direction when turning angles of 45 and $90^{\circ}$ are used, respectively. A turning angle of $45^{\circ}$ causes a stronger phase shift compared with a turning angle of $90^{\circ}$. Meanwhile, the wave amplitudes in the $90^{\circ}$ case are closer to the simulated wave amplitude than in the $45^{\circ}$ case. Since in this simulation the wave vector is $32^{\circ}$ away from the orbit, a turning angle closer to this wave vector will be affected more by the variations along the LOS. Thus, the reconstructed wave in Fig. 11b fits better with the simulated wave than in Fig. 11a.

\subsection{Across-track horizontal wavelength}

From the retrieval results in Sect. 4.3, we can see that the across-track horizontal wavelength retrieval is affected by the sweep-mode turning angle in two aspects. First, the horizontal coverage in the across-track direction is limited by this turning angle. When $\alpha=45^{\circ}$, the tangent points from individual limb sounding measurements could extend to $\sim 1700 \mathrm{~km}$ apart from the orbital plane. A larger value of this turning angle will increase the across-track distance that the tangent points are able to reach. Second, the across-track horizontal resolution, which determines the smallest detectable wavelength of a wave, is also affected by this turning angle. As the across-track horizontal resolution increases with distance, smaller waves can be observed better in the region 

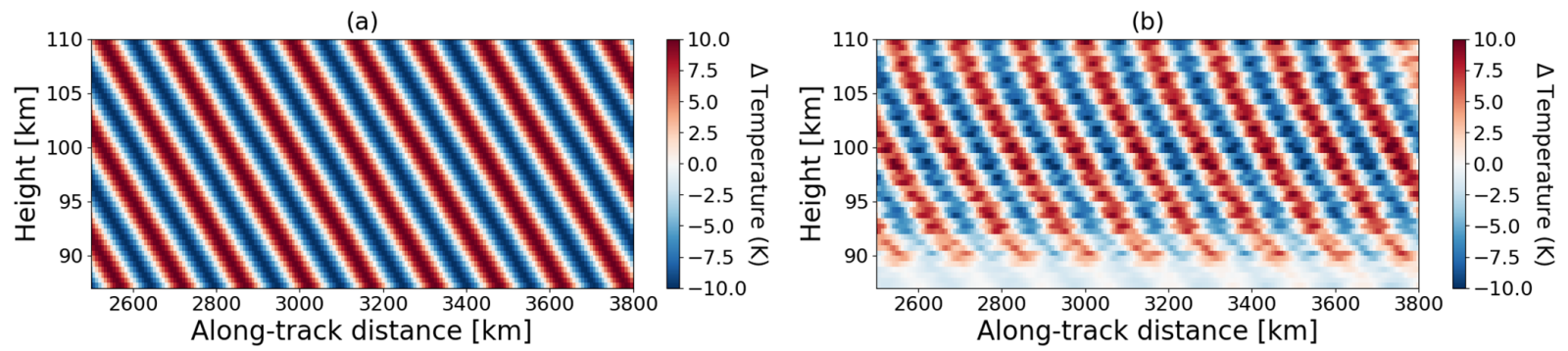

Figure 10. Simulated GW (a) with a vertical wavelength of $10 \mathrm{~km}$ and horizontal wavelength of $150 \mathrm{~km}$, and retrieved wave structure (b) assuming a turning angle $\alpha$ of $0^{\circ}$.
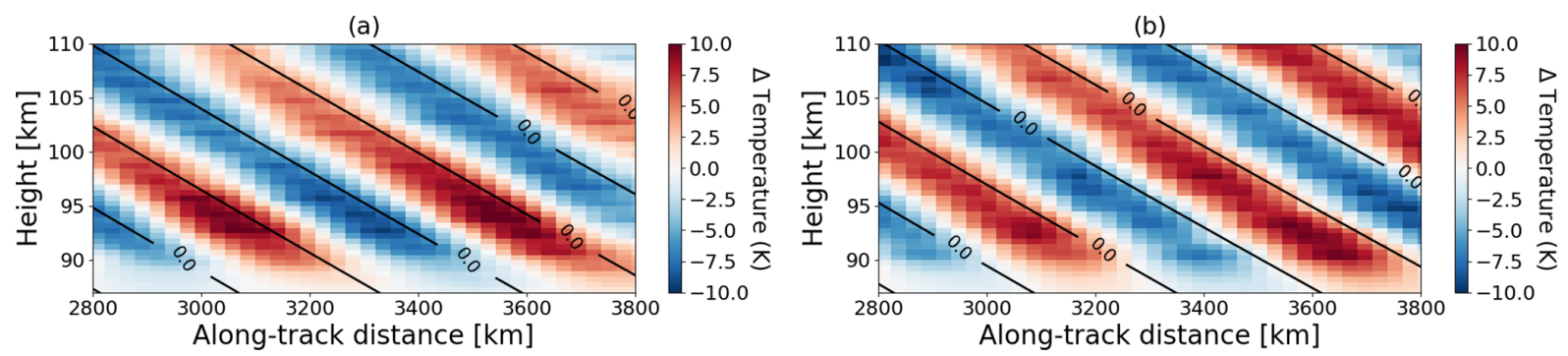

Figure 11. Comparison of wave structured retrieved in the along-track direction using a turning angle of $45^{\circ}$ (a) and $90^{\circ}$ (b). The wave is simulated with a vertical wavelength of $15 \mathrm{~km}$ and a horizontal wavelength of $425 \mathrm{~km}$. The wave vector is tilted at an angle of $32^{\circ}$ away from the flight direction. The simulated wave amplitude is $10 \mathrm{~K}$. The phase fronts with zero value of the simulated wave are indicated by the black lines.

further away from the orbit. This means GWs with smaller horizontal wavelengths in the across-track direction can be observed if the satellite is operated in the sweep mode with a larger turning angle.

Figure 12 shows an example of retrieving a GW in the across-track direction with a turning angle $\alpha$ of $90^{\circ}$. In this example, the horizontal coverage in the across-track direction extends to $2200 \mathrm{~km}$ because a large value of $\alpha$ is selected. Between $\sim 400$ and $1000 \mathrm{~km}$ in the across-track direction, the wave structure can barely be seen as the sampling distance is relatively coarse $(\sim 200 \mathrm{~km})$. In the region close to $\sim 2200 \mathrm{~km}$ the tangent points are densely distributed in the across-track direction, and therefore GWs with a small horizontal wavelength can be resolved.

Based on the discussion above, Fig. 13 gives the result associated with its ability in resolving horizontal wavelengths under different viewing modes. In the along-track direction, the smallest horizontal wavelength that can be resolved is constant $(\sim 85 \mathrm{~km})$ because the sampling distance in this direction is independent of the turning angle. In the across-track direction, the resolvable horizontal wavelength is $\sim 850 \mathrm{~km}$ at a turning angle of $10^{\circ}$. GWs with a smaller across-track horizontal wavelength can be resolved if a larger turning angle is adopted. For an idealized atmosphere and idealized observation, horizontal wavelengths in the across-track direction down to a few kilometers can be resolved. When the turning angle is $45^{\circ}$, the resolvable hor- izontal wavelength in both directions reaches the same limit of $\sim 85 \mathrm{~km}$.

\subsection{Horizontal wavelength estimation}

From conventional limb sounding measurements, the resolved horizontal wavelength is the apparent wavelength projected along the orbital track. This projected horizontal wavelength is generally larger than the real wavelength of a wave; for details, see Ern et al. (2004) and Trinh et al. (2015). Utilizing this sweep-mode observation strategy, projected wavelengths can be retrieved along and across the orbit track in two independent slices. This retrieval scheme could reduce the bias for the estimation of the real wavelength of a wave. The relationship between the retrieved horizontal wavelengths and the real wavelength is shown in Fig. 14. The satellite track is represented by the dark-blue arrow. The wave fronts of the GW are indicated by the light-blue shading. The retrieved horizontal wavelength in the along-track direction $\left(\lambda_{1}\right)$ is represented by the red bar, and that in the across-track direction $\left(\lambda_{c}\right)$ is represented by the yellow bar. However, the real horizontal wavelength of this simulated wave is the one that is represented by the black bar. In any case, the real horizontal wavelength of a wave can be derived by combining the horizontal wavelengths retrieved in the two directions perpendicular to each other. The main advantage of this observation mode is that the accuracy of retrieved horizontal wavelengths is independent of the angle between the 

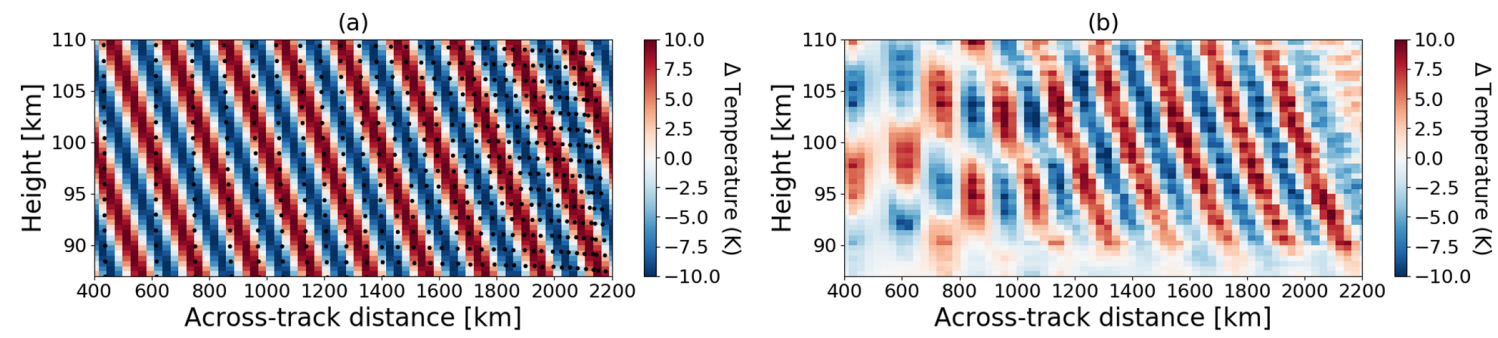

Figure 12. Simulated GW (a) with a vertical wavelength of $10 \mathrm{~km}$ and horizontal wavelength of $250 \mathrm{~km}$, and retrieved wave structure (b) assuming a turning angle $\alpha$ of $90^{\circ}$. The tangent points from individual measurements are marked as white circles in (a).

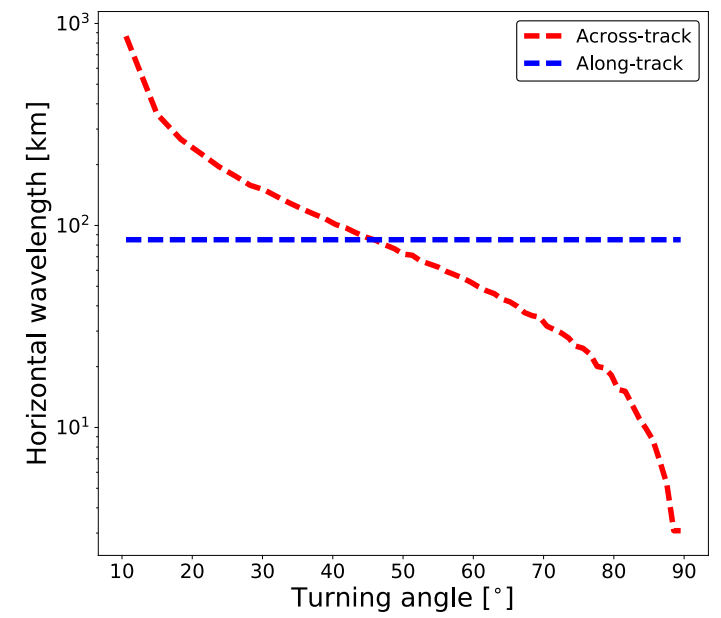

Figure 13. Comparison of the ability in resolving horizontal wavelength along the two directions under different turning angles. The blue line represents the minimal detectable horizontal wavelength in the along-track direction, and the red line represents that in the across-track direction. This sensitivity curve is obtained based on the simulation of idealized atmosphere and observation.

satellite track and horizontal wave vector. Following a geometric transformation, an unbiased horizontal wavelength estimation can be obtained using this equation:

$\lambda_{\mathrm{h}}=\frac{\lambda_{1} \lambda_{\mathrm{c}}}{\sqrt{\lambda_{1}^{2}+\lambda_{\mathrm{c}}^{2}}}$.

\section{Conclusions}

The three-dimensional tomographic reconstruction technique has been used in airborne instruments in recent years. Studies for the satellite mission concept PREMIER have also demonstrated the feasibility of resolving fine GW structures with tomographic retrievals. In this work, a sweep-mode observation strategy, which can be used by spaceborne limb sounding instruments for the retrieval of full 3-D wave vectors in the middle atmosphere is presented.

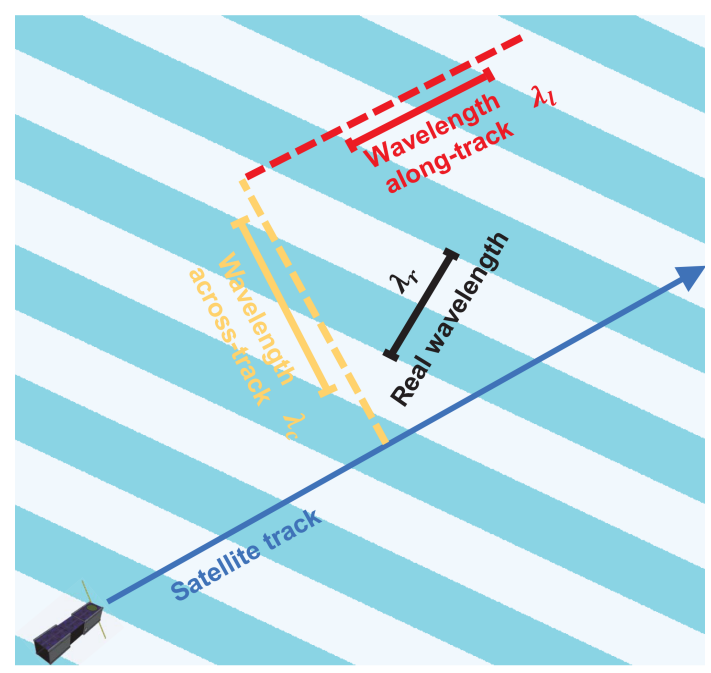

Figure 14. Schematic drawing of observed horizontal wavelength in the sweep-mode observation. The wave fronts of the GW are indicated by the light-blue shading. The satellite track is represented by the dark-blue arrow. The retrieved horizontal wavelengths in the along- and across-track directions are represented by yellow and red bars, respectively. The real horizontal wavelength is represented by the black bar.

An end-to-end simulation of this observation strategy is executed for an instrument measuring the $\mathrm{O}_{2}$ A-band airglow emissions in the MLT region. Employing this approach, two projected 2-D wave structures can be retrieved in the direction along and across the orbital track, respectively. The turning angular velocity of the instrument needs to be adapted in a way such that the two vertical slices are exactly perpendicular to each other. This special case can be realized by the expected capabilities of the envisaged satellite platform. The spatial resolution and coverage of the retrieved wave structures in both directions are related to the turning angle of this observation mode and have been analyzed in the paper. The smallest horizontal wavelength that can be resolved in the along-track direction is constant $(\sim 85 \mathrm{~km})$ for all turning angles, whereas it decreases with increasing turning angle in the across-track direction. The wave vectors retrieved in the two directions are then used to deduce the real horizontal 
wavelength of a wave. This reconstruction technique is independent of the angle between the orbital track and wave fronts. It provides an unbiased estimation of the real horizontal wavelength of GWs, which is an important parameter for the calculation of GW momentum flux.

The sweep mode as performed here is a large improvement beyond the capabilities of conventional limb sounders that observe with a LOS limited to a fixed azimuth.

Data availability. All data used in this work are available from the authors upon request (r.song@fz-juelich.de and m.kaufmann@fzjuelich.de).

Competing interests. The authors declare that they have no conflict of interest.

Acknowledgements. This work was supported in part by the National Natural Science Foundation of China under grant 41590852 and the China Scholarship Council (201404910513).

The article processing charges for this open-access

publication were covered by a Research

Centre of the Helmholtz Association.

Edited by: Markus Rapp

Reviewed by: two anonymous referees

\section{References}

Alexander, M. J. and Barnet, C.: Using Satellite Observations to Constrain Parameterizations of Gravity Wave Effects for Global Models, J. Atmos. Sci., 64, 1652-1665, https://doi.org/10.1175/JAS3897.1, 2007.

Alexander, M. J., Gille, J., Cavanaugh, C., Coffey, M., Craig, C., Eden, T., Francis, G., Halvorson, C., Hannigan, J., Khosravi, R., Kinnison, D., Lee, H., Massie, S., Nardi, B., Barnett, J., Hepplewhite, C., Lambert, A., and Dean, V.: Global estimates of gravity wave momentum flux from High Resolution Dynamics Limb Sounder observations, J. Geophys. Res.-Atmos., 113, D15S18, https://doi.org/10.1029/2007JD008807, 2008.

Alexander, M. J., Geller, M., McLandress, C., Polavarapu, S., Preusse, P., Sassi, F., Sato, K., Eckermann, S., Ern, M., Hertzog, A., Kawatani, Y., Pulido, M., Shaw, T. A., Sigmond, M., Vincent, R., and Watanabe, S.: Recent developments in gravity-wave effects in climate models and the global distribution of gravitywave momentum flux from observations and models, Q. J. Roy. Meteor. Soc., 136, 1103-1124, https://doi.org/10.1002/qj.637, 2010.

Babcock, H. D. and Herzberg, L.: Fine Structure of the Red System of Atmospheric Oxygen Bands, Astrophys. J., 108, 167-190, https://doi.org/10.1086/145062, 1948.

Buehler, S., Eriksson, P., Kuhn, T., von Engeln, A., and Verdes, C.: ARTS, the atmospheric radiative trans- fer simulator, J. Quant. Spectrosc. Ra., 91, 65-93, https://doi.org/10.1016/j.jqsrt.2004.05.051, 2005.

Carlotti, M., Dinelli, B. M., Raspollini, P., and Ridolfi, M.: Geo-fit approach to the analysis of limb-scanning satellite measurements, Appl. Opt., 40, 1872-1885, https://doi.org/10.1364/ORS.2001.OWC5, 2001.

Chandran, A., Rusch, D. W., Merkel, A. W., Palo, S. E., Thomas, G. E., Taylor, M. J., Bailey, S. M., and Russell, J. M.: Polar mesospheric cloud structures observed from the cloud imaging and particle size experiment on the Aeronomy of Ice in the Mesosphere spacecraft: Atmospheric gravity waves as drivers for longitudinal variability in polar mesospheric cloud occurrence, J. Geophys. Res.-Atmos., 115, D13102, https://doi.org/10.1029/2009JD013185, 2010.

Eckermann, S. D. and Preusse, P.: Global Measurements of Stratospheric Mountain Waves from Space, Science, 286, 1534-1537, https://doi.org/10.1126/science.286.5444.1534, 1999.

Ehard, B., Kaifler, B., Kaifler, N., and Rapp, M.: Evaluation of methods for gravity wave extraction from middle-atmospheric lidar temperature measurements, Atmos. Meas. Tech., 8, 46454655, https://doi.org/10.5194/amt-8-4645-2015, 2015.

Ern, M., Preusse, P., Alexander, M. J., and Warner, C. D.: Absolute values of gravity wave momentum flux derived from satellite data, J. Geophys. Res.-Atmos., 109, D20103, https://doi.org/10.1029/2004JD004752, 2004.

Ern, M., Lehmann, C., Kaufmann, M., and Riese, M.: Spectral wave analysis at the mesopause from SCIAMACHY airglow data compared to SABER temperature spectra, Ann. Geophys., 27, 407416, https://doi.org/10.5194/angeo-27-407-2009, 2009.

Ern, M., Preusse, P., Gille, J. C., Hepplewhite, C. L., Mlynczak, M. G., Russell, J. M., and Riese, M.: Implications for atmospheric dynamics derived from global observations of gravity wave momentum flux in stratosphere and mesosphere, J. Geophys. Res.-Atmos., 116, D19107, https://doi.org/10.1029/2011JD015821, 2011.

Ern, M., Hoffmann, L., and Preusse, P.: Directional gravity wave momentum fluxes in the stratosphere derived from highresolution AIRS temperature data, Geophys. Res. Lett., 44, 475485, https://doi.org/10.1002/2016GL072007, 2017.

Fetzer, E. J. and Gille, J. C.: Gravity Wave Variance in LIMS Temperatures. Part I: Variability and Comparison with Background Winds, J. Atmos. Sci., 51, 2461-2483, https://doi.org/10.1175/15200469(1994)051<2461:GWVILT>2.0.CO;2, 1994.

Forbes, J. M., Russell, J., Miyahara, S., Zhang, X., Palo, S., Mlynczak, M., Mertens, C. J., and Hagan, M. E.: Tropospherethermosphere tidal coupling as measured by the SABER instrument on TIMED during July-September 2002, J. Geophys. Res.Space, 111, A10S06, https://doi.org/10.1029/2005JA011492, 2006.

Friedl-Vallon, F., Gulde, T., Hase, F., Kleinert, A., Kulessa, T., Maucher, G., Neubert, T., Olschewski, F., Piesch, C., Preusse, P., Rongen, H., Sartorius, C., Schneider, H., Schönfeld, A., Tan, V., Bayer, N., Blank, J., Dapp, R., Ebersoldt, A., Fischer, H., Graf, F., Guggenmoser, T., Höpfner, M., Kaufmann, M., Kretschmer, E., Latzko, T., Nordmeyer, H., Oelhaf, H., Orphal, J., Riese, M., Schardt, G., Schillings, J., Sha, M. K., Suminska-Ebersoldt, O., and Ungermann, J.: Instrument concept of the imaging Fourier 
transform spectrometer GLORIA, Atmos. Meas. Tech., 7, 35653577, https://doi.org/10.5194/amt-7-3565-2014, 2014.

Fritts, D. C. and Alexander, M. J.: Gravity wave dynamics and effects in the middle atmosphere, Rev. Geophys., 41, 1003, https://doi.org/10.1029/2001RG000106, 2003.

Fritts, D. C., Janches, D., Iimura, H., Hocking, W. K., Mitchell, N. J., Stockwell, R. G., Fuller, B., Vandepeer, B., Hormaechea, J., Brunini, C., and Levato, H.: Southern Argentina Agile Meteor Radar: System design and initial measurements of largescale winds and tides, J. Geophys. Res.-Atmos., 115, D18112, https://doi.org/10.1029/2010JD013850, 2010.

Geller, M. A., Alexander, M. J., Love, P. T., Bacmeister, J., Ern, M., Hertzog, A., Manzini, E., Preusse, P., Sato, K., Scaife, A. A., and Zhou, T.: A Comparison between Gravity Wave Momentum Fluxes in Observations and Climate Models, J. Climate, 26, 6383-6405, https://doi.org/10.1175/JCLI-D-12-00545.1, 2013.

Hoffmann, L. and Alexander, M. J.: Retrieval of stratospheric temperatures from Atmospheric Infrared Sounder radiance measurements for gravity wave studies, J. Geophys. Res.-Atmos., 114, D07105, https://doi.org/10.1029/2008JD011241, 2009.

Hoffmann, P., Becker, E., Singer, W., and Placke, M.: Seasonal variation of mesospheric waves at northern middle and high latitudes, J. Atmos. Sol.-Terr. Phy., 72, 1068-1079, https://doi.org/10.1016/j.jastp.2010.07.002, 2010.

Hoffmann, P., Rapp, M., Singer, W., and Keuer, D.: Trends of mesospheric gravity waves at northern middle latitudes during summer, J. Geophys. Res.-Atmos., 116, D00P08, https://doi.org/10.1029/2011JD015717, 2011.

John, S. R. and Kumar, K. K.: TIMED/SABER observations of global gravity wave climatology and their interannual variability from stratosphere to mesosphere lower thermosphere, Clim. Dynam., 39, 1489-1505, https://doi.org/10.1007/s00382-012-13299, 2012.

Kaufmann, M., Blank, J., Guggenmoser, T., Ungermann, J., Engel, A., Ern, M., Friedl-Vallon, F., Gerber, D., Grooß, J. U., Guenther, G., Höpfner, M., Kleinert, A., Kretschmer, E., Latzko, Th., Maucher, G., Neubert, T., Nordmeyer, H., Oelhaf, H., Olschewski, F., Orphal, J., Preusse, P., Schlager, H., Schneider, H., Schuettemeyer, D., Stroh, F., Suminska-Ebersoldt, O., Vogel, B., M. Volk, C., Woiwode, W., and Riese, M.: Retrieval of threedimensional small-scale structures in u pper-tropospheric/lowerstratospheric composition as measured by GLORIA, Atmos. Meas. Tech., 8, 81-95, https://doi.org/10.5194/amt-8-81-2015, 2015.

Kaufmann, M., Deiml, M., Olschewski, F., Mantel, K., Wagner, F., Loosen, F., Fröhlich, D., Rongen, H., Neubert, T., Rottland, B., Schneider, H., Riese, M., Knieling, P., Liu, J., Song, R., Wroblowski, O., Chen, Q., Koppmann, R., Solheim, B., Shan, J., and Shepherd, G.: A miniaturized satellite payload hosting a spatial heterodyne spectrometer for remote sensing of atmospheric temperature, in: IAA Symposium, Berlin, Germany, 2017.

Krisch, I., Preusse, P., Ungermann, J., Dörnbrack, A., Eckermann, S. D., Ern, M., Friedl-Vallon, F., Kaufmann, M., Oelhaf, H., Rapp, M., Strube, C., and Riese, M.: First tomographic observations of gravity waves by the infrared limb imager GLORIA, Atmos. Chem. Phys., 17, 14937-14953, https://doi.org/10.5194/acp-17-14937-2017, 2017.
Lindzen, R. S.: Turbulence and stress owing to gravity wave and tidal breakdown, J. Geophys. Res.-Oceans, 86, 9707-9714, https://doi.org/10.1029/JC086iC10p09707, 1981.

Liu, X., Yue, J., Xu, J., Wang, L., Yuan, W., Russell, J. M., and Hervig, M. E.: Gravity wave variations in the polar stratosphere and mesosphere from SOFIE/AIM temperature observations, J. Geophys. Res.-Atmos., 119, 7368-7381, https://doi.org/10.1002/2013JD021439, 2014.

Liu, X., Yue, J., Xu, J., Garcia, R. R., Russell, J. M., Mlynczak, M., Wu, D. L., and Nakamura, T.: Variations of global gravity waves derived from 14 years of SABER temperature observations, J. Geophys. Res.-Atmos., 122, 6231-6249, https://doi.org/10.1002/2017JD026604, 2017.

Livesey, N. J. and Read, W. G.: Direct retrieval of line-of-sight atmospheric structure from limb sounding observations, Geophys. Res. Lett., 27, 891-894, https://doi.org/10.1029/1999GL010964, 2000.

Medvedev, A. and Klaassen, G.: Parameterization of gravity wave momentum deposition based on nonlinear wave interactions: basic formulation and sensitivity tests, J. Atmos. Sol.-Terr. Phy., 62, 1015-1033, https://doi.org/10.1016/S1364-6826(00)00067$5,2000$.

Nakamura, T., Higashikawa, A., Tsuda, T., and Matsushita, Y.: Seasonal variations of gravity wave structures in $\mathrm{OH}$ airglow with a CCD imager at Shigaraki, Earth Planets Space, 51, 897-906, https://doi.org/10.1186/BF03353248, 1999.

Pautet, D. and Moreels, G.: Ground-based satellite-type images of the upper-atmosphere emissive layer, Appl. Opt., 41, 823-831, https://doi.org/10.1364/AO.41.000823, 2002.

Placke, M., Hoffmann, P., Becker, E., Jacobi, C., Singer, W., and Rapp, M.: Gravity wave momentum fluxes in the MLT-Part II: Meteor radar investigations at high and midlatitudes in comparison with modeling studies, J. Atmos. Sol.-Terr. Phy., 73, 911920, https://doi.org/10.1016/j.jastp.2010.05.007, 2011.

Preusse, P., Dörnbrack, A., Eckermann, S. D., Riese, M., Schaeler, B., Bacmeister, J. T., Broutman, D., and Grossmann, K. U.: Space-based measurements of stratospheric mountain waves by CRISTA 1 . Sensitivity, analysis method, and a case study, J. Geophys. Res.-Atmos., 107, 8178, https://doi.org/10.1029/2001JD000699, 2002.

Remsberg, E. E., Gordley, L. L., Marshall, B., Thompson, R., Burton, J., Bhatt, P., Harvey, V., Lingenfelser, G., and Natarajan, M.: The Nimbus 7 LIMS version 6 radiance conditioning and temperature retrieval methods and results, J. Quant. Spectrosc. Ra., 86, 395-424, https://doi.org/10.1016/j.jqsrt.2003.12.007, 2004.

Riese, M., Spang, R., Preusse, P., Ern, M., Jarisch, M., Offermann, D., and Grossmann, K. U.: Cryogenic Infrared Spectrometers and Telescopes for the Atmosphere (CRISTA) data processing and atmospheric temperature and trace gas retrieval, J. Geophys. Res.-Atmos., 104, 16349-16367, https://doi.org/10.1029/1998JD100057, 1999.

Riese, M., Friedl-Vallon, F., Spang, R., Preusse, P., Schiller, C., Hoffmann, L., Konopka, P., Oelhaf, H., von Clarmann, T., and Höpfner, M.: GLObal limb Radiance Imager for the Atmosphere (GLORIA): Scientific objectives, Adv. Space Res., 36, 989-995, https://doi.org/10.1016/j.asr.2005.04.115, 2005.

Rocken, C., Anthes, R., Exner, M., Hunt, D., Sokolovskiy, S., Ware, R., Gorbunov, M., Schreiner, W., Feng, D., Herman, B., Kuo, Y.H., and Zou, X.: Analysis and validation of GPS/MET data in 
the neutral atmosphere, J. Geophys. Res.-Atmos., 102, 2984929866, https://doi.org/10.1029/97JD02400, 1997.

Rothman, L., Gordon, I., Babikov, Y., Barbe, A., Benner, D. C., Bernath, P., Birk, M., Bizzocchi, L., Boudon, V., Brown, L., Campargue, A., Chance, K., Cohen, E., Coudert, L., Devi, V., Drouin, B., Fayt, A., Flaud, J.-M., Gamache, R., Harrison, J., Hartmann, J.-M., Hill, C., Hodges, J., Jacquemart, D., Jolly, A., Lamouroux, J., Roy, R. L., Li, G., Long, D., Lyulin, O., Mackie, C., Massie, S., Mikhailenko, S., Müller, H., Naumenko, O., Nikitin, A., Orphal, J., Perevalov, V., Perrin, A., Polovtseva, E., Richard, C., Smith, M., Starikova, E., Sung, K., Tashkun, S., Tennyson, J., Toon, G., Tyuterev, V., and Wagner, G.: The HITRAN2012 molecular spectroscopic database, J. Quant. Spectrosc. Ra., 130, 4-50, https://doi.org/10.1016/j.jqsrt.2013.07.002, 2013.

Schmidt, H., Brasseur, G. P., Charron, M., Manzini, E., Giorgetta, M. A., Diehl, T., Fomichev, V. I., Kinnison, D., Marsh, D., and Walters, S.: The HAMMONIA Chemistry Climate Model: Sensitivity of the Mesopause Region to the 11-Year Solar Cycle and CO2 Doubling, J. Climate, 19, 3903-3931, https://doi.org/10.1175/JCLI3829.1, 2006.

Schroeder, S., Preusse, P., Ern, M., and Riese, M.: Gravity waves resolved in ECMWF and measured by SABER, Geophys. Res. Lett., 36, L10805, https://doi.org/10.1029/2008GL037054, 2009.

Song, R., Kaufmann, M., Ungermann, J., Ern, M., Liu, G., and Riese, M.: Tomographic reconstruction of atmospheric gravity wave parameters from airglow observations, Atmos. Meas. Tech., 10, 4601-4612, https://doi.org/10.5194/amt-104601-2017, 2017.

Suzuki, S., Shiokawa, K., Otsuka, Y., Ogawa, T., and Wilkinson, P.: Statistical characteristics of gravity waves observed by an allsky imager at Darwin, Australia, J. Geophys. Res.-Atmos., 109, D20S07, https://doi.org/10.1029/2003JD004336, 2004.

Suzuki, S., Nakamura, T., Ejiri, M. K., Tsutsumi, M., Shiokawa, K., and Kawahara, T. D.: Simultaneous airglow, lidar, and radar measurements of mesospheric gravity waves over Japan, J. Geophys. Res.-Atmos., 115, D24113, https://doi.org/10.1029/2010JD014674, 2010.

Tikhonov, A. N. and Arsenin, V. I.: Solutions of ill-posed problems, Scripta series in mathematics, Winston; distributed solely by Halsted Press, Washington: New York, 1977.
Trinh, Q. T., Kalisch, S., Preusse, P., Chun, H.-Y., Eckermann, S. D., Ern, M., and Riese, M.: A comprehensive observational filter for satellite infrared limb sounding of gravity waves, Atmos. Meas. Tech., 8, 1491-1517, https://doi.org/10.5194/amt-8-1491-2015, 2015.

Tsuda, T., Nishida, M., Rocken, C., and Ware, R. H.: A Global Morphology of Gravity Wave Activity in the Stratosphere Revealed by the GPS Occultation Data (GPS/MET), J. Geophys. Res.-Atmos., 105, 7257-7273, https://doi.org/10.1029/1999JD901005, 2000.

Ungermann, J., Hoffmann, L., Preusse, P., Kaufmann, M., and Riese, M.: Tomographic retrieval approach for mesoscale gravity wave observations by the PREMIER Infrared Limb-Sounder, Atmos. Meas. Tech., 3, 339-354, https://doi.org/10.5194/amt-3339-2010, 2010.

Ungermann, J., Blank, J., Lotz, J., Leppkes, K., Hoffmann, L., Guggenmoser, T., Kaufmann, M., Preusse, P., Naumann, U., and Riese, M.: A 3-D tomographic retrieval approach with advection compensation for the air-borne limb-imager GLORIA, Atmos. Meas. Tech., 4, 2509-2529, https://doi.org/10.5194/amt-4-25092011, 2011.

Vallance Jones, A.: Aurora Geophysics and Astrophysics Monographs, D. Reidel, Hingham, Mass, 1974.

Vincent, R. A.: The dynamics of the mesosphere and lower thermosphere: a brief review, Progress in Earth and Planetary Science, 2, 4, https://doi.org/10.1186/s40645-015-0035-8, 2015.

Ward, W. E.: A simple model of diurnal variations in the mesospheric oxygen nightglow, Geophys. Res. Lett., 26, 3565-3568, https://doi.org/10.1029/1999GL003661, 1999.

Wright, C. J., Osprey, S. M., Barnett, J. J., Gray, L. J., and Gille, J. C.: High Resolution Dynamics Limb Sounder measurements of gravity wave activity in the 2006 Arctic stratosphere, J. Geophys. Res.-Atmos., 115, D02105, https://doi.org/10.1029/2009JD011858, 2010.

Wu, D. L.: Mesoscale gravity wave variances from AMSU-A radiances, Geophys. Res. Lett., 31, L12114, https://doi.org/10.1029/2004GL019562, 2004. 